\title{
LIVROS DE AREIA: EM BUSCA DE UMA CHAVE HERMENÊUTICA PARA A HISTORIOGRAFIA DO DESIGN
}

\author{
BOOKS OF SAND: IN SEARCH OF A HERMENEUTICAL KEY FOR THE \\ HISTORIOGR APHY OF DESIGN
}

WANDYR HAGGE ${ }^{1}$

RESUMO: Cabe, em geral, à História a missão de ordenar um passado vago e virtualmente infinito transformando-o em narrativas que buscam neutralizar o improvável e construir realidades que deem sentido e inteligibilidade ao tempo e aos objetos sobre os quais ele se desdobra. Mas que misterioso poder é esse que tem uma pessoa que escreve História. O poder de transformar o "nada" - ou o "quase-nada" das fontes nem sempre reais (ou precisas) -, em "verdades". Em busca de um estatuto epistêmico próprio, é possível concluir que a História não existe; o que existe são "historiografias"; interpretações. A reflexão filosófica que estuda a natureza teórica da historiografia, nos diversos objetos históricos passíveis de contemplação é, nesse sentido, essencialmente hermenêutica. Esse texto se debruça sobre a fatuidade de se fazer história e, em particular, sobre o desafio de se pensar (teoricamente) a história do design.

Palavras-chave: Design, História, Historiografia, Hermenêutica

ABSTRACT: In general, the scope of History is to organize a vague (and virtually infinite) past, building narratives which aim to render the present as much intelligible as possible. The historian has, in this sense, a mysterious power: the power of choosing and transforming cloudy and often imprecise sources into plausible "truths". But History does not exist in itself. We can only reach "ways of making History"; historiography, interpretations... In the modern days, it can be argued that History has become Hermeneutics. But to transform Hermeneutics into History it is necessary to develop tools of translation in order to convey meanings to the relations between present and past. This paper delves upon the fatuity of making History, as a whole, and, in particular, of thinking (theoretically) the challenges of writing the History of Design.

Key-words: Design, History, Historiography, Hermeneutics

\footnotetext{
1 - O autor agradece os membros do Grupo de Estudos sobre Design, Epistemologia e Moralidade (DEMO) que se reúne na ESDI/UERJ, e em particular a Daniel Portugal e a Gustavo Silvano, pelas discussões que resultaram nesse texto. Erros e omissões são, evidentemente, de minha própria responsabilidade. Professor da ESDI/UERJ. Email: wandyr@gmail.com
} 


\title{
O QUE É HISTÓRIA?
}

\author{
"The sands of time are quicksands... (...) So much can sink into \\ them without a trace. And what a blessing when those things that \\ sink away are needless worries". \\ Margaret Atwood - The Year of the Flood. \\ "Para ver una cosa hay que comprenderla. [...] Si viéramos \\ realmente el universo, tal vez lo comprenderíamos." \\ Jorge Luis Borges El Congreso. in: E1 Libro de Arena.
}

Jorge Luis Borges entrou na minha vida antes de Michel Foucault ou Hans-Georg Gadamer: Tlön, Uqbar, Orbis Tertius - conto publicado no livro Ficciones -, me atingiu como uma pedrada; me afetou como uma vertigem. Procuro, enquanto escrevo, um sinônimo para "vertigem": penso em "tontura", em "aturdimento", em "perturbação"; e até mesmo em "delírio". Pois foi tudo isso e, ainda hoje quero crer, algo mais. ${ }^{2}$

Não foi, nesse sentido, sem algo de espanto que, ao folhear o Prólogo do Les Mots e les Choses - um trabalho que acreditava ser de "não-ficção" -, em uma estante da livraria Leonardo da Vinci, no centro do Rio, encontrei a menção ao Emporio celestial de conocimientos benévolos (que aparecera em Otras Inquisiciones, de Borges). E, sem pensar duas vezes, resolvi comprar o livro. Comprei o livro sem mesmo saber muito bem do que se tratava. Nessa época - e lá se vão quase quarenta anos! -, estudante de graduação em Economia na UFRJ, eu mal sabia quem era "Michel Foucault".

Devo a Borges, a Foucault, a Gadamer e a um vago conceito de "História" a estrutura desse texto.

Retiro de Otras Inquisiciones outra referência à pena de Borges. Nesse caso, um apólogo atribuído a Han Yü - alegado prosista do século IX cuja estatura, na literatura chinesa, Charles Hartman - especialista -, compara à de Dante, Shakespeare ou à de Goethe, no Ocidente. ${ }^{3}$ Han Yü

\footnotetext{
2 - O conto, publicado na coletânea, Ficciones já havia aparecido no jornal argentino Sur, em 1940. Em 1980, ganhei um exemplar da tradução de Carlos Nejar, saído pela Editora Globo dez anos antes. As referências, nesse texto, remetem a BORGES, Jorge Luis. Obras completas: (1923-1972). Volume 1, Buenos Aires, Emece, 1974.

3 - HARTMAN, Charles. "Han Yü”. in: NIENHAUSER Jr., William H. (Ed.) (1986): The Indiana Companion to Traditional Chinese Literature. Indiana University Press, p. 397.
} 
é, segundo Borges, citado na Anthologie Raisonée de la Littérature Chinoise, de Georges Margouliès (1948) como autor do seguinte texto: ${ }^{4}$

\begin{abstract}
"Universalmente se admite que el unicornio es com ser sobrenatural y de buen agüero; así lo declaran las odas, los anales, las 98eguridade de varones ilustres y otros textos cuya 98eguridade es indiscutible. Hasta los párvulos y las mujeres del 98 eguri saben que el unicornio constituye com presagio favorable. Pero este animal no figura entre los animales domésticos, no siempre es fácil encontrarlo, no se presta a uma clasificación. No es como lo caballo o el toro, el lobo o el ciervo. Com tales condiciones, podríamos estar frente al unicornio y no sabríamos com 98eguridade que lo es. Sabemos que tal animal com crin es caballo y que tal animal com cuernos es toro. No sabemos como es el unicornio". 5
\end{abstract}

A História é como o unicórnio: se não a vemos é porque não a reconhecemos. E se a reconhecemos é porque a imaginamos.

O arqueólogo e historiador francês Paul Veyne, ao (tentar) definir "História" em um verbete da Encyclopaedia Universalis usa as seguintes palavras:

"A palavra 'história' designa tanto aquilo que aconteceu como o relato do que
aconteceu; a história é, pois, quer uma sequência de acontecimentos, quer o relato
dessa sequência de acontecimentos. Estes ocorreram realmente: a história é um
relato de acontecimentos verdadeiros, ao contrário, por exemplo, do que
acontece com um romance. Através desta norma de verdade, a história, como
disciplina, aparenta-se com a ciência; ela é uma atividade de conhecimento". ${ }^{6}$

Veyne não se dá ao trabalho de definir "Romance" ou "Ciência", aqui; conceitos não triviais. Contenta-se em sugerir que os romances lidam com acontecimentos não "verdadeiros" - seja lá o que isso for -, e mesmo que não são capazes de gerar "conhecimento".

Em Como se Escreve a História, Veyne desenvolve o tema um pouco mais:

"[O que é a História?] (...) [A] resposta a essa pergunta não mudou nesses dois mil e duzentos anos que se passaram desde sua descoberta pelos sucessores de Artistóteles: os historiadores narram fatos reais que têm o homem como ator; a história é um romance real. Resposta que, à primeira vista, não parece dizer muita coisa"...7

E continua - complicando ainda mais seu argumento:

"A história não é uma ciência e não tem muito a esperar das ciências; ela não explica e não tem método; melhor ainda, a História, da qual muito se tem falado nesses dois últimos séculos, não existe". (VEYNE, 1982, p. 12)

\footnotetext{
4 - Borges (1952/1974, p. 710) grifa Margouliè o sobrenome do autor; sem o prenome. O mesmo livro aparece no site wordcat.org. Lá, o nome do mesmo autor aparece com diversas grafias: G Mergoulies, Georges Margouliès; George Margouliès; G. Margoulies; G.Margouliès.

5 - BORGES; Jorge Luis. Op. Cit. 1974, p. 710.

6 - VEYNE, Paul. "Introdução". in: História e historicidade. Tradução de Geminiano Cascais Franco, Lisboa, Gradiva, 1988, p. 9.

7 - VEYNE, Paul. (1971): Comment on écrit l'histoire. Tradução de Alda Baltar e Maria Auxiliadora Kneipp: Como se escreve a história; Foucault Revoluciona a História. Brasília, Editora da Universidade de Brasília, 1982, p. 12.
} 
Arrematando, em seguida:

“(...) [O]s historiadores, em cada época, têm a liberdade de recortar a história a seu modo (em história política, erudição, biografia, etnologia, sociologia, história natural), pois a história não possui articulação natural". (VEYNE, 1982, p. 28)

Em suma: a história não é ficção e tampouco ciência. Mas seria o quê?

No livro Foucault, Sa pensée, sa personne (1978), Veyne avança um pouco mais seu conceito de História (comentando a essência da obra do próprio Foucault):

“(...) Primo, o que está em jogo na história humana, para lá mesmo do poder, da economia, etc., é a verdade. (...) Secundo, o conhecimento histórico, por seu lado, se quiser levar a bom termo as análises de uma dada época, terá de atingir, para além da sociedade ou da mentalidade, as verdades gerais nas quais os escritos dessa época estavam, sem saber, encerrados, quais peixes num aquário". 8

Entende-se, nesse sentido, que a história é dinâmica, que não se pode circunscrever apenas ao contexto em que foi vivida e que, portanto, não se limita aos "acontecimentos" do passado. Entende-se, ademais, que todo conhecimento histórico é mediado (por "verdades") do presente (das quais não pode escapar).

Em termos toscos, pois, a História tem tanto a ver com o presente como com o passado. Independentemente de como, onde e quando foi escrita. Hans-Georg Gadamer descreveu esse fenômeno com precisão:

"A história das tribos esquimós norte-americanas é, com toda certeza, bastante
independente de possíveis influências dessas tribos sobre a 'história universal da
Europa'. Entretanto (...) qualquer um que leia, daqui a cinquenta ou cem anos,
uma história dessas tribos escrita em nossos dias não apenas achará esta história
desatualizada (pois, com o correr do tempo, saber-se-á interpretar as fontes mais
corretamente) como também será capaz de perceber que, na década de sessenta,
as fontes eram lidas diferentemente porque as pessoas eram movidas por
questões, preconceitos e interesses diferentes".?

Certo. A história não existe em nuvens. Conforme visto acima, ela sobrevive dentro de "tradições" que são transmitidas no tempo (ou que são perdidas ou esquecidas nesse mesmo tempo); cobertas ou descobertas. Tradições que chegam a nós oralmente, por textos, e por mídias conhecidas (ou que ainda aparecerão).

$\mathrm{Na}$ história - paradoxalmente -, convivem as ideias de se atingir uma "verdade" e a noção de que essa verdade não existe (e que jamais existiu ou existirá). Nem mesmo se pudéssemos viajar

\footnotetext{
8 - VEYNE. Paul. (2008): Foucault, Sa pensée, sa personne. Tradução de Luís Lima: Foucault, O pensamento, a pessoa. Lisboa, Edições Texto e Grafia, p. 10.

9 - GADAMER, Hans-Georg. (1960): Wahrheit und Methode. Tradução de Garrett Barden e John Cumming: Truth and Method. New York, Crossroad, 1985, p. xx. Tradução para o português minha.
} 
no tempo poderíamos, realmente, saber a "verdade" da História... Recorrendo a Veyne uma outra vez:

\begin{abstract}
"Ainda que eu tivesse sido contemporâneo e testemunha de Waterloo, ainda que tivesse sido seu principal ator, Napoleão em pessoa, teria apenas uma perspectiva sobre o que os historiadores chamarão o evento Waterloo; só poderia deixar para a posteridade o meu depoimento que, se chegasse até ela, seria chamado de indício. Mesmo que eu tivesse sido Bismarck ao tomar a decisão de despachar o telegrama de Sem, minha própria interpretação dos acontecimentos não seria, talvez, a mesma que a de meus amigos, do meu confessor, do meu historiador e do meu psicanalista, que poderia ter suas próprias versões sobre a minha decisão e julgar saber melhor do que eu o que eu desejava". (VEYNE, 1982, p. 18)
\end{abstract}

Em última análise, a história é sempre hospedeira de algum veículo de Tradições que ou hibernam em fontes ou que chegam (por qualquer acaso) até um determinado ponto do futuro. E, se é possível concordar que a história não existe - como o sugere Veyne -, por outro lado, não podemos deixar de salientar que o que existe, de fato, são historiografias. E que as historiografias disputam o rigor de explicar o passado tal como se ele fosse uma realidade.

E - por mais que se queira negar a ideia de "ciência" da história -, o "rigor" cobrado das interpretações dos eventos históricos e o fato de que história se faz entre "historiadores" (que são seres que vivem em grupo) fará sempre com que uma interpretação (dentre várias) predomine dentro de um debate (dados critérios que variarão, certamente, no tempo, na geografia, na metodologia, etc.) A história é construída por humanos e, como tal, está sujeita a "humanidades"...

Jacques Revel acrescenta ao que já foi dito a seguinte crítica, salientando o papel do debate acadêmico:

"Ao menos em teoria, o debate constitui uma das práticas científicas normais. Em suas versões mais clássicas, a história das ciências habituou-nos a ver o debate como uma das formas mais legítimas da condição e do progresso científicos. Ela fez isso, frequentemente, explicando o antes pelo depois, em uma perspectiva teleológica que parece impor-se com mais evidência por tratar-se de uma história de saberes, quer dizer, de uma evolução que parece dever ir de um menos a um mais. O debate é geralmente apresentado como um momento obrigatório do progresso, uma crise necessária e, finalmente, salutar, no momento em que a verdade, ou, pelo menos, maior verdade, se impõe. A mise en scène que constituímos em objeto na narrativa histórica obedece a convenções dramatúrgicas relativamente simples e convincentes. Ela tem o inconveniente de ser anacrônica. Sugere, de fato, a leitura do conjunto do debate a partir de seu ponto de chegada - de seu resultado -, a partir, portanto, da posição que dele resulta e que, em seguida, seja aceita como de modo mais ou menos permanente. O grande risco de tal tratamento é o de levar ao esquecimento quais foram as condições efetivas do debate em um dado momento em que nenhuma solução ainda se impunha, no qual, sobretudo, a configuração desenhada pelas posições 
confrontadas ainda não estava estabilizada, nem claramente definida por seus protagonistas". ${ }^{10}$

Chegamos aqui a um ponto conclusivo: sendo (ou não sendo); postulando (ou não postulando) "rigor" - ou "cientificidade" -, o jogo de lembranças e de esquecimentos que caracteriza a essência das historiografias leva diretamente à questão da hermenêutica em sua totalidade: a interpretação de um "passado" que se "revela" por "fontes" que necessitam ser "interpretadas" para que delas se extraia algum "sentido".

A História, portanto, de fato não existe. Ela não é, necessariamente, um "romance". Tampouco é uma "ciência". O próprio passado não é um livro; uma Escritura. História, nesse sentido, é Historiografia. E Historiografia é, por assim dizer, Hermenêutica. Mas que tipo de Hermenêutica?

\section{O QUE É HERMENÊUTICA?}

Trata-se de uma pergunta que pode ser respondida de diversas maneiras. Comecemos pelo básico: o termo «hermenêutica» vem do grego e relaciona-se ao deus mensageiro Hermes. A raiz grega da palavra hermenêutica - hermenenien, conta-nos Richard E. Palmer $-{ }^{11}{ }^{11}$ costuma ser traduzida como «interpretan». Mas vai além disso: pode ser compreendida como dizer (exprimir em voz alta), explicar e, também, traduzirir (como na tradução de uma língua para outra). ${ }^{12}$

Historicamente, o termo «hermenêutica» surge (pela primeira vez na modernidade) como uma teoria da explicação dos textos sagrados. Particularmente no século XVII, quando as disputas religiosas exigiam rigor na interpretação «verdadeira» das Escrituras, tratar-se-ía de uma disciplina de muita utilidade. Assim, em 1654 é publicado o Hermeneutica sacre sive methodus exponendarum sacrarum litterarum, de J. C. Danhauer (onde a palavra «hermenêutica» aparece utilizada pela primeira vez com este sentido). ${ }^{13} \mathrm{Na}$ explicação de Palmer, a tendência geral da hermenêutica bíblica seria a tentativa da construção de um «(...) "sistema" de interpretação a partir do qual as passagens obscuras (...) [pudessem] ser interpretadas. (...) Há uma procura de um "princípio hermenêutico» que sirva de guia». ${ }^{14}$

Todavia, com o passar do tempo, a utilização da palavra - e mormente do método -tornouse mais abrangente, passando a incorporar não apenas a interpretação de textos bíblicos, mas

\footnotetext{
10 - REVEL, Jacques. (1999): "História e ciências sociais: Leituras de um debate francês". in: Proposições: Ensaios de História e Historiografia. Rio de Janeiro, EdUERJ, 2009, pp. 15-16.

11 - PALMER, Richard E. (1969): Hermeneutics - Interpretation Theory in Schleiermacher, Dilthey, Heidegger and Gadamer. Tradução de Maria Luísa Ribeiro Ferreira: Hermenêutica. Lisboa, Edições 70, 1986, p. 23.

12 - PALMER, Op.Cit., p. 24.

13 - PALMER, Op.Cit., p. 44.

14 - PALMER, Op.Cit., p.. 46.
} 
também a interpretação de quaisquer textos de significado obscuro. ${ }^{15}$ Tal fato provocou um alargamento do campo da hermenêutica, e, nesse sentido, fez com que ela incorporasse elementos de uma metodologia filológica: a verdadeira tarefa do intérprete passou a ser histórica. Não se tratava mais apenas de compatibilizar o todo com as partes de acordo com regras de coerência interna. Tratava-se, antes, de descortinar uma verdade primordial que fora ocultada pela passagem do tempo:

«A tarefa da exegese era (...) entrar profundamente no texto, usando as ferramentas da razão natural e encontrando aquelas grandes verdades morais que os escritores do Novo Testamento pretendiam, verdades escondidas sob diferentes termos históricos». ${ }^{16}$

Ao assumir o ideário da filologia, no entanto, a hermenêutica abriu-se para o mundo dos textos «profanos». E, logo, a Bíblia - objeto privilegiado inicial -, passou a ser apenas mais um dentre tantos objetos sobre os quais a hermenêutica lançava sua luz. Mas a hermenêutica foi além. Com Schleiermacher ampliou ainda mais suas fronteiras; passou a ter como objetivo ser uma «ciência» ou uma «arte» «(...) que descreve as condições da compreensão em qualquer diálogo». ${ }^{17}$

Assim, ultrapassaram-se os limites da hermenêutica filológica e caminhou-se no sentido de uma hermenêutica geral. O próximo passo foi dado por Wilhelm Dilthey para quem a hermenêutica teria funcionado como uma base metodológica para as Ciências do Espírito (Geisteswissenschaften). O problema de Dilthey residia em encontrar interpretações «objetivamente válidas» para «expressões da vida interior». ${ }^{18}$ Para tanto, era necessário fundamentar os limites da compreensão humana de forma análoga à que Kant fez com relação à Matemática e às Ciências da Natureza. ${ }^{19}$

Entretanto, a compreensão do mundo das Ciências do Espírito não deriva (acreditava Dilthey) do mesmo tipo de percepção que aquela difundida pelas Ciências Naturais: seria preciso que fossem criados seus próprios cânones. Tal foi a tarefa de que Dilthey se incumbiu: rejeitando a epistemologia das Ciências Naturais, tentou fundar as bases da compreensão humana em sua essência psicológica. Assim, para Dilthey, a compreensão do humano era diferente da compreensão da Natureza e a ela não poderia ser reduzida:

«Chamamos de compreensão (Verstehen) ao processo pelo qual, com a ajuda de signos percebidos do exterior através dos sentidos, conhecemos uma interioridade. (...) A compreensão da natureza - 102nterpretativo naturae - é uma expressão figurada. (...) Chamamos de compreensão ao processo através do qual

15 - PALMER, Op.Cit., p. 45.

16 - PALMER, Op.Cit., p. 49.

17 - PALMER, Op.Cit., p. 50.

18 - PALMER, Op.Cit., p. 105.

19 - BLEICHER, Joseph. (1980): Contemporary Hermeneutics: Hermeneutics as Method, Philosophy and Critique. London, Routledge \& Kegan Paul, 1983, p. 19. 
conhecemos algo de psíquico partindo de signos sensíveis que são manifestação do psíquico». ${ }^{20}$

Richard Palmer (a quem recorremos ainda uma vez) sintetiza este ponto nos seguintes termos:

«Dilthey determinou que a experiência concreta e não a especulação tem que ser o único ponto de partida admissível para uma teoria das Geisteswissenschaften. (...) A experiência concreta, histórica e viva tem que ser o ponto de partida e o ponto de chegada das Geisteswissenschaftenı. ${ }^{21}$

Com Dilthey, a hermenêutica atinge seu ponto culminante no século XIX.

$$
* * *
$$

Eis, portanto, o contexto do surgimento da hermenêutica: fornecer legitimidade à interpretação de textos sagrados, em primeiro lugar e, depois, aliar-se à Razão contra as forças nocivas da superstição, da tradição e da autoridade. Para cumprir tal insigne missão, um dos caminhos (já vimos com Descartes) consiste em buscar apoio em um ponto de Arquimedes; uma fundação inequívoca que nos ampare em qualquer circunstância. Para Dilthey, esse fundamento vem a ser a objetividade da experiência (psicológica) comum:

«Qualquer expressão humana representa algo que é comum a muitos e,
conseqüentemente, faz parte do reino da mente objetiva. Cada palavra ou frase,
cada gesto ou forma de cortesia, cada obra de arte ou feito histórico só é
compreensível porque a pessoa que tenta se comunicar e a pessoa que
compreende estão conectadas por algo que têm em comum; os indivíduos
sempre experimentam, pensam, agem, e também compreendem dentro desta
esfera comum».22

Ou seja, porque sou humano, posso entender as manifestações da cultura humana. Isto desde que eu me aproxime do objeto desejado do entendimento com a mente aberta e tentando livrarme de todos os preconceitos possíveis. Para tanto, devo colocar-me no lugar do autor. Mas devo almejar conhecer sua obra melhor que ele próprio! Ora, tamanha façanha seria conseguida mediante treinamento específico. Seria necessário um metodo. Assim: «Temos, (...) a tradição de Schleiermacher e de Dilthey, cujos partidários encaram a hermenêutica como um corpo geral de princípios metodológicos que subjazem à interpretação». ${ }^{23}$

\footnotetext{
20 - DILTHEY, Wilhelm. «Origens da Hermenêutica». in: MAGALHÃES, Rui (org.):Textos de Hermenêutica. Tradução de Alberto Reis, Porto, Rés, 1984, p. 150.

21 - PALMER, Op. Cit., p. 105.

22 - Wilhelm Dilthey apud OUTHWAITE, William.. «Hans-Georg Gadamen». in: SKINNER, Quentin (ed.) ((1985):

The Return of Grand Theory in Social Science. Canto Books. Cambridge, Cambride University Press, 1990, p. 24. Tradução minha.

23 - PALMER, Op. Cit., p. 55.
}

Cadernos Cajuína, V. 5, N. 2, 2020, p. 96-114. 
Por outro lado, neste século desenvolveu-se uma outra corrente (rival). Uma corrente que colocará a ênfase não no método mas no caráter histórico da compreensão de qualquer manifestação cultural. Entre eles «(...) temos, (...) os seguidores de Heidegger que vêem a hermenêutica como uma exploração filosófica das características e dos requisitos necessários a toda a compreensão». ${ }^{24}$

Tomemos o locus classicus da profissão de fé heideggeriana; a definição da historicidade da compreensão (tal como exposta na Introducão à Metafísica):

«1. A determinação da essencialidade do homem nunca é resposta mas essencialmente questão.

2. A investigação dessa questão é Histórica no sentido originário, segundo o qual é essa investigação, que instaura pela $1^{\mathrm{a}}$. vez o acontecer Histórico.

3. E é assim, porque a questão, o que é o homem, só pode ser investigada dentro da questão sobre o Ser.

4. Somente, quando o Ser se abre na investigação, processa-se o acontecer Histórico e, com isso, aquele ser do homem em virtude do qual ele se atreve a uma disputa com o ente como tal.

5. Tal disputa, que se mantém numa atitude de investigação, faz o homem retornar ao ente que ele mesmo é e deve ser.

6. Somente numa investigação Histórica o homem chega a si mesmo e é uma pessoa. (...)

7. Por ser, enquanto Histórico, ele mesmo, a questão sobre o seu ser específico tem de se transformar da forma: "o que é o homem"? na forma "quem é o homem"?».25

Em termos objetivos: com Heidegger, o significado ontológico da compreensão é revelado; isto é, ficou claro pela primeira vez que o problema da compreensão não é um problema metodológico, mas sim ontológico.

Temos, assim, o ponto de partida da hermenêutica de Hans-Georg Gadamer, que William Outhwaite resume nos seguintes termos:

«Duas idéias são (...) centrais no trabalho filosófico do hermeneuta alemão HansGeorg Gadamer: a compreensão encarada, primeiro como um processo holístico mediado por uma moldura complexa e, segundo, como um processo ativo de encontro e resposta. A idéia da compreensão como moldura ele compartilha com o resto da tradição hermenêutica; a ênfase na compreensão como um ato de engajamento é um tema que ele toma emprestado de Heidegger mas que acaba transformando em seu». ${ }^{26}$

Esta atitude que Heidegger e Gadamer demonstram com respeito à historicidade da compreensão revela-se interessante: é graças a ela que se torna possível romper com o legado

24 - PALMER, Op. Cit., p. 55.

25 - HEIDEGGER, Martin. (1935): Einführung in die Metaphysik. Tradução de Emmanuel Carneiro Leão: Introdução à Metafísica. 2. ed. Rio de Janeiro, Tempo Brasileiro, 1978, pp. 166-167.

26 - OUTHWAITE, Op. Cit., p. 23. 
«fundacionista» cartesiano. De fato, a hermenêutica de Gadamer rompe com a tradição na medida em que não supõe mais a libertação dos preconceitos como ideal de interpretação. Mais do que isso: rejeita-se a idéia de que a compreensão pode ser atingida apenas observando-se algum tipo de método. Pelo contrário. Na Introdução de seu Wahrbeit und Methode, publicado inicialmente em 1960 (com uma segunda edição importante em 1965), Gadamer deixa claro:

«A investigação que se segue começa a partir da resistência vivenciada pela ciência moderna contra a pretensão universal do método científico. Empenha-se em buscar aquela experiência da verdade que transcende a esfera de controle do método científico onde quer que este possa ser encontrado, bem como em questionar sua legitimidade. Assim, as ciências humanas aliam-se a formas de experiência que se encontram no exterior da ciência: com as experiências da filosofia, da arte, e da própria história. Em todos esses campos de experiência, a verdade que é comunicada não pode ser verificada pelos meios metodológicos típicos da ciência» ${ }^{27}$

Adiante, Gadamer ratifica: «(...) Preocupamo-nos com as verdades que ultrapassam os limites do conhecimento metódico». ${ }^{28}$

Nesse sentido, Gadamer continua,

«O propósito de minha investigação não é o de apresentar uma teoria geral da interpretação e um relato diferenciado de seus métodos (...) mas de descobrir o que existe em comum a todas as modalidades de compreensão, além de mostrar que a compreensão não é nunca um comportamento subjetivo com relação a um determinado «objeto» qualquer, mas em relação a sua história efetiva - a história de sua influência; em outras palavras, a compreensão pertence ao ser daquilo que é compreendido». ${ }^{29}$

Bref: Gadamer rejeita a vigência de um modelo de verdade análogo ao das Ciências Naturais no campo das «Ciências do Espírito». Como conseqüência, ele rejeita a ênfase em uma relação sujeito/objeto tradicional substituindo-a por uma relação entre sujeito e bistória do objeto. Assim sendo, os preconceitos e os pré-juízos deixam de aparecer apenas de forma negativa: eles acabam sendo veículos através dos quais as idéias se transportam dentro das tradições. Nas palavras de Outhwaite, «Nossa compreensão de um texto deriva de nossa posição em uma tradição histórica e este é precisamente nosso elo com a influência histórica (ou a efetividade) do texto propriamente dita»..$^{30}$

Diante desta constatação, torna-se quase ridículo que o intérprete tenha como ideal anularse diante de um texto (para que apenas a voz do autor seja ouvida). Outhwaite continua:

${ }^{27}$ - GADAMER, Hans-Georg. (1965): Wahrheit und Methode. Tradução de Garrett Barden e John Cumming: Truth and Method. New York, Crossroad, p. xii. Tradução minha para o português.

28 - GADAMER, Op. Cit. p. xiii, tradução minha.

29 - GADAMER, Op. Cit., p. xix. Tradução minha.

30 - OUTHWAITE, Op. Cit., p. 25. Tradução minha. 
«Compreender não significa esquecer nosso horizonte de significados para que possamos nos colocar dentro dos limites de um texto ou de uma sociedade estranhos; significa, antes, unir ou fundir nosso horizonte com o deste texto (ou desta sociedade)». (1990, p. 25)

Esse texto - esse «horizonte» com o qual fundimos nosso próprio horizonte -, não é independente da própria tradição que possibilitou que ele se tornasse acessível ao leitor: pertence a ela. Assim sendo, os preconceitos e os juízos prévios são mais do que aparentam: eles são a própria realidade histórica do ser. Essa realidade histórica é definida a partir do presente.

Quanto ao passado? Ele está perdido e não poderá jamais ser reconstruído:

«O que é reconstruído - uma vida ressuscitada de um passado perdido -, não é a vida original. Em sua continuidade arrebatada da origem, ela adquire apenas uma existência cultural, secundária... Mesmo um quadro retirado de um museu e recolocado na igreja ou o edifício restaurado à sua condição de origem não são mais o que uma vez foram; tornam-se apenas atrações turísticas. Semelhantemente, a hermenêutica que considera a compreensão como a reconstrução do original não seria nada mais do que a recuperação de um significado morto. (...) A natureza essencial do espírito histórico não consiste na restauração do espírito histórico, mas na mediação consciente com a vida contemporânea»ı. ${ }^{31}$

Significa isso que devemos abandonar a idéia de uma «interpretação verdadeira»? Não. Significa que o ato de interpretar se desenrola como em um jogo. Um jogo ao qual escolhemos nos dedicar. Um jogo que tem regras, ao qual nos entregamos e por quem somos dominados. Um jogo que é movimento e que a cada momento apresenta movimentos «legítimos» que se redefinem no tabuleiro em função da participação dos outros jogadores. Em suma, o jogo tem sua verdade; mas não é uma verdade (e tampouco $a$ verdade).

Sumariemos as principais conclusões às quais se pode chegar a paratir da reflexão sobre a hermenêutica gadameriana. Mas tomemos, agora, como base, o inventário proposto por Andrés Ortiz-Osés, em seu Antropologia Hermenêutica. Para Ortiz-Osés, a hermenêutica de Gadamer pode ser resumida a sete principais pontos, quais sejam:

a) O conhecimento propriamente dito diz compreensão; compreensão diz interpretação e interpretação diz linguagem, quer dizer, integração na e pela linguagem.

b) A interpretação é então uma transposição (tradução) de uma linguagem (texto) para a nossa linguagem. Toda a interpretação é, pois, transformação do interpretado para a nossa condicionalidade.

c) Esta transformação, que induzimos em todo o trabalho hermenêutico, háde adaptar-se no entanto ao objeto (...) como ao seu modelo de verificação. $\mathrm{O}$ critério da hermenêutica continua a ser a mensuratio ad rem.

31 - GADAMER, Op. Cit., pp. 149-150. 
d) Toda a interpretação é, enquanto tal, dialéctica, quer dizer, objectivosubjectiva. Mas esta dialéctica, longe de opor o sujeito ao objecto - e vice-versa reintegra a interpretação no regime universal da interpretação histórica (da história: em e desde ela). Intérprete e intepretado, ficam ambos sob a direção de sentido que a própria história impõe enquanto interpretação efectiva ineludível (Wirkungsgeschichte). A História é a que primeiramente interpreta, desenvolvendo as possibilidades e sentidos ocultos, com base na dicção e reedição que o tempo como acontecimento humano fundamental impõe.

e) Esta história, sujeito da nossa própria interpretação, acaba por ser linguagem, texto a comprovar, jogo a conjugar, diálogo a realizar. Portanto, a verdade é um acontecer (...) que nos acontece, mas não sem a nossa própria colaboração e acordo verdadeiro (...) que pode apresentar a forma privada do des-acordo - que não é senão um acordo implícito - "correctivo" dessa história. f) A relação radical mediadora (...) entre objeto e sujeito de interpretação entende-se sobre a base de uma crítica ontológica da obra de arte: a obra de arte como a história, como o jogo - é mais sujeito do que objeto de interpretação. Assim como a essência de uma obra artística radica, em cada caso, como a da história e a do jogo, na sua auto-expressão e auto-exposição (...) ou representação, assim também as nossas interpretações são meros órgãos interpretativos válidos em cada caso da realidade feita linguagem, e a julgar de acordo com as regras que o jogo impõe: "são" esta mesma realidade como tal, quer dizer, como realidade com sentido e inteligibilidade. Interpretar é interpretar-se, e interpretar-se é ser interpretado pela auto-interpretação que a própria realidade leva a cabo como "história lingüística". g) Interpretação é, pois, "linguagem" (...). A linguagem é assim o medium em que tanto o objeto (texto) como o sujeito (intérprete; ator) ficam dissolvidos. Interpretar é, portanto, deixar que a linguagem diga o que nos tem a dizer».32

Chegamos onde poderíamos chegar: não existe verdade fora da interpretação. Não existe interpretação fora da linguagem. A linguagem, a História e o Ser se misturam. O Ser é um evento da linguagem e nele se move... Tão consciente quanto um peixe dentro d'água...

O conhecimento histórico traduz uma relação entre um sujeito ("real" ou "imaginário", socialmente construído) e a(s) narrativas de identidade de objetos - igualmente "reais" ou imaginário" e igualmente socialmente construídos -, (tal como transportadas pelas Tradições) em constante transmutação.

\section{O QUE É DESIGN?}

Para quem não é familiar ao campo, um pequeno sinal já deve alertar sobre a complexidade dessa definição: não existe o verbete Design na The Design Encyclopaedia, de Mel Byars. Na edição de 1994, do verbete "Derby Silver" passa-se ao verbete "Design and Industries Association (DIA)". Na edição de 2004, o verbete sobre a DIA citado acima) é antecedido por uma curta biografia de "Pietro Derossi’. Na introdução, o autor confessa:

32 - ORTIZ-OSÉS, Andrés. (1983): Antropologia Hermenêutica. Tradução de Laura Ferrereira dos Santos: Antropologia Hermenêutica. Lisboa, Escher, 1989, pp. 55-57. 
“Embora o objeto deste livro seja design, o uso da palavra 'design'é problemático. Design passou a ter acepções que podem ser tanto abstratas como concretas. No entanto, o contexto, aqui, supõe uma concretude específica: o design de um objeto que possui uma função. Esta definição genérica separa o design das belas artes. Tal distinção é discutível e nem sempre absoluta pois existem áreas cinzentas onde o artesanato (craft) e as artes decorativas fundem-se com o desenho industrial". 33

Para remediar essa "ausência", o autor propõe verbetes que "acomodam" o problema em categorias tais como "pessoas", "grupos", "instituições", e "temas relacionados". Ou seja, "improvisa" - caso a caso -, de acordo com a interpretação (subjetiva) dos autores dos verbetes (dada a curadoria geral do autor do Dicionário, evidentemente).

Já o Design Dictionary, editado em Alemão e em Inglês pelo Board of International Research in Design, inicia o verbete que procura definir design - escrupulosamente redigido pelos próprios editores -, literalmente pedindo desculpas machadianas:

"Correndo o risco de desapontá-lo, caro leitor, é impossível fornecer uma definição única e confiável (authoritative ) para o termo central deste dicionário: design. As origens históricas do design são complexas e sua própria natureza - o que é e o que não é -, sujeita a diversos e incessantes debates, como se pode observar pelas próprias perspectivas apresentadas neste Dicionário". ${ }^{34}$

Em sequência a esta velada declaração de impotência, Erhloff e Marshall "definem” design evocando sua História: de uma suposta "academia” fundada por Leonardo da Vinci até a descrição de "estilos", "escolas" e "movimentos" da modernidade (tais como, por exemplo, Arts \& Crafts, Art Nouveau, Deutsche Werkbund, Baubaus, etc.). ${ }^{35}$

É inútil, nesse sentido, sumariar as tentativas de "definir" design. Tantas foram as tentativas que o empreendimento virou motivo de anedota, como se percebe na afirmação do arquiteto mexicano Luis Rodríguez Morales:

"Tudo parece indicar que um dos passatempos prediletos da teoria do design é encontrar novas definições para a atividade. Trata-se de um trabalho constante independentemente de a atividade do design em si não mudar em si mesma". 36

\footnotetext{
33 - BYARS, Mel. (1994): The Design Encyclopaedia. London/New York, Laurence King /MOMA, 2004, p. 7. Tradução minha.

34 - ERLHOFF, Michael \& MARSHALL, Timothy. (Eds.) (2003): Design Dictionary: Perspetives on Design Terminology. Basel, Birkhäuser, 2008, p. 104. Tradução minha. Erloff e Marshall até mesmo observam que existem discrepâncias no uso dos termos nas próprias línguas em que o livro foi publicado. Ou seja, as edições em Alemão e em Inglês registram discrepâncias relacionadas às próprias traduções.

35 - Sobre a Academia Vinciana, Ehrloff e Marshall parecem desconhecer que diversos autores - inclusive Sigmund Freud, além de especialistas -, questionam sua existência: “Também é fantasia, provavelmente, a 'Academia Vinciana', que se supôs existir graças a cinco ou seis emblemas altamente elaborados que têm o nome da academia. Vasari menciona tais desenhos, mas não a instituição". Ver FREUD, Sigmund. Obras Completas (1909 - 1910): Cinco lições sobre psicanálise. Volume XI. Tradução Brasileira de Durval Marcondes modificada por Jayme Salomão. Rio de Janeiro, Imago, 1996, p. 41.

36 - MORALES, Luis Rodríguez. (1989): Para una Teoría del Diseño. Cidade do México, Universidad Autónoma Metropolitana de Azcapotzalco, 2008.
} 
De fato, qualquer um que se aventure nesse universo encontrará definições das mais amplas - como a de Victor Papanek -, às mais precisas - como a de Greg Bamford. A título de exemplo, ei-las abaixo. Para Papanek, inicia seu (já clássico) Design for the Real World com as seguintes palavras: “Todos os seres humanos são designers. E o que fazemos a maior parte do tempo é design porque o design é básico para qualquer atividade humana". ${ }^{37}$

Para Greg Bamford, por outro lado:

“Alguém projeta (designs) o artefato $X$ no tempo $t$ se, e somente se:

1. Esse alguém imagina ou descreve $X$ no momento $t$;

2. Ao mesmo tempo em que supões que $X$, pelo menos parcialmente, satisfaz algum conjunto de requisitos $R$, sob as condições $C$; e

3. De modo que, ao satisfazer $R$ dá-se resposta a um problema para o qual,

4. X e uma solução nova ou original." 38

De um lado e de outro - da vaguidão ao formalismo -, a teoria do design sempre cai em algum tipo de armadilha tal como a formulada na anedota de Diógenes de Sínope: um bípede sem plumas não é necessariamente um ser humano; pode ser, por exemplo, uma galinha.

Diante desse dilema epistemológico real, o historiador Rafael Denis sintetiza o problema da seguinte maneira: o design se define por seus objetos ou por seu processo? E prossegue:

(...) Se o design é definido pelos objetos que produz, conforme argumenta a maioria das autoridades modernistas, então só aquelas atividades que geram uma produção de natureza industrial podem ser enquadradas na definição. Seguindo este raciocínio até a sua conclusão lógica, uma pessoa que projeta uma cadeira ou um cartaz para ser produzido manualmente não está praticando design; está fazendo artesanato ou arte. Se, por outro lado, a definição do design se pauta no próprio processo de projetar, então pouco importa, a rigor, a forma de produção. Levando novamente o argumento ao extremo, mesmo que não haja produção nenhuma, a atividade de design continua a existir. Sob esta ótica, o projeto constitui o produto por excelência do designer e a sua aplicação passaria a ser uma questão secundária, de reprodução mecânica. ${ }^{39}$

Segue-se, para Denis que - independentemente da dificuldade de definir design com precisão conceitual -, essa relação dialética deve levar em consideração que “(...) a discussão sobre as origens históricas do design deve tratar prioritariamente da demarcação do design como atividade autonôma e do surgimento do designer como profissional". ${ }^{40}$

Em suma, "ser no mundo" - trabalhando sub specie temporis -, não é possível definir o design sem explicar o que faz o designer. Mas o designer - e seja lá a que tipo de designer nos estamos

37 - PAPANEK, Victor. Design for the Real World: Human Ecology and Social Change. London, Pantheon Books, 1972, p. 3. Tradução minha.

38 - Greg BAMFORD Apud. PARSONS, Glenn. The Philosophy of Design. Cambridge, Polity Press, p. 10.

39 - DENIS, Rafael Cardoso. (1998) “Design, Cultura Material e o Fetichismo dos Objetos”. in: Arcos. Volume 1. Número Único, pp. 15-16.

40 - DENIS, Rafael Cardoso. Op. Cit., p. 19. 
referindo -, está, obviamente, inserido em uma cultura que se correlaciona com formas de produzir, de adquirir e de utilizar. Ou seja, não é possível entender "design" ou "designer" na ausência da investigação de um sentido conferido pela historicidade de sua relação com o mundo. Pensar o design, assim - seguindo Kjetil Fallan -, não é mais apenas estudar a relação entre objetos e seus criadores e sim “(...) cada vez mais a história das relações, transcrições, transações, transposições e transformações que constituem os relacionamentos entre coisas, pessoas e ideias". ${ }^{41}$

Voltamos, aqui, à História. Voltamos, aqui, à Hermenêutica. Voltamos aqui, portanto, às areias: "Se você seguir continuamente a linha da lógica, mais cedo ou mais tarde chega num ponto onde percebe que a lógica termina, mas a jornada continua". ${ }^{42}$

\section{EM BUSCA DE UMA CHAVE...}

"Ya a nadie le importan los hechos. Son meros puntos de partida para la invención y el razonamiento. En las escuelas nos enseñan la duda y el arte del olvido." Jorge Luis Borges Utopia de un hombre que está cansado. in: El Libro de Arena.

De que maneira é possível pensar uma História do Design?

Vimos, com Gadamer, que a compreensão pertence ao ser daquilo que é compreendido. E que o ato de interpretar supõe uma relação entre o sujeito e a história do objeto onde o campo se define como um jogo (com suas regras específicas) que comportam "verdades" mas que não são verdades em si mesmas.

A História do Design - como disciplina -, é uma construção recente. Começou a tomar seus contornos modernos no século XX; na Inglaterra da década de $1970 .{ }^{43}$ O estímulo para isso, de acordo com Victor Margolin, decorreu de uma instrução da burocracia educacional inglesa no sentido de incorporar disciplinas de história da arte e do design à formação dos cursos (predominantemente politécnicos) das áreas de Arquitetura ou Design.

Não é difícil inferir que os primeiros cursos teriam uma natureza de cultura geral e que visavam, sobretudo, informar alunos sobre a identidade da profissão que viriam abraçar. Em princípio, a própria figura do historiador do Design não existia; a historiografia foi "importada de outras áreas". Entre os paradigmas mais importantes se poderia mencionar, por um lado, a História

41 - FALLAN, Kjetil. Design History: Understanding theory and method. Oxford, Berg, p. 20.

42 - OSHO. (1991): The Wisdom of the Sands. Tradução de Swami Anand Nisargan: A Sabedoria das Areias: Discursos sobre o Sufismo. Volume I [1978/1999], p.15.

43 - Ver, por exemplo, MARGOLIN, Victor. "História do Design e Estudos em Design". in: A Política do

Artificial. Tradução de Cid Knipel Moreira. Rio de Janeiro, Civilização Brasileira, 2014. 
da Arquitetura e, por outro, a História da Tecnologia. ${ }^{44}$ A primeira das abordagens produziu uma narrativa rica em "heróis" e "objetos". A segunda, ao contrário, privilegiou o que se poderia chamar de "design anônimo".

Durante os primeiros anos de "formação" da disciplina construiu-se um caminho básico: a Revolução Industrial; o movimento de Artes e Ofícios, na Inglaterra; o Art Nouveau, na Europa e Deutscher Werkbund e Bauhaus como contribuições (industrializantes) alemãs. A cronologia que acompanhava esta narrativa - embora variasse um pouco de acordo com os diversos autores -, não fugia muito de um marco inicial com a Exposição Universal de Londres, em 1851 terminando com o fechamento da escola de Baubaus, em 1933.

Com o passar do tempo - sobretudo com a entrada no século XXI -, e na medida em que o processo de industrialização (e a própria profissão de designer) foram se espalhando pelo mundo, diversas "anomalias" - para abusar do termo kuhniano -, ${ }^{45}$ foram ficando claras. E, nesse sentido, um curioso fenômeno historiográfico se processou: a atividade do design passou a ser encontrada em outros lugares do mundo (além da Europa) e começou a recuar no tempo. ${ }^{46}$

Refletindo sobre esse contexto, o teórico Richard Buchanan conjecturou que há basicamente quatro pontos de partida para uma história (genérica) do design: a Criação do Universo; a análise de Imagens e Objetos Pré-Históricos; a Revolução Industrial; e, finalmente, o Século XX. Buchanan expôs esse pensamento em um ensaio de 1995, intitulado Rhetoric, Humanism and Design. ${ }^{47}$ A fundamentação para a tipologia, de acordo com Buchanan, se apóia nos seguintes pontos. Há quem defenda que o design, como atividade, só aparece claramente no século XX (na medida em que se estabelece uma metodologia do design e a formalização da profissão. Outros alegam que as origens devem ser buscadas na Revolução Industrial, com a transformação dos instrumentos de produção e das condições sociais do trabalho. Outros, ainda, argumentam que é com a criação dos primeiros objetos e imagens que o design deve ser buscado. E, finalmente, há os que acreditam em primórdios que se confundem com a própria criação do Universo, por Deus. Buchanan expõe esse pensamento de acordo com a figura abaixo: ${ }^{48}$

\footnotetext{
44 - Tomem-se, como exemplos, dois clássicos. O primeiro - do historiador da arte e da arquitetura Nikolaus Pevsner -, Pioneers of the Modern Movement: From William Morris to Walter Gropius, publicado em 1936, será o paradigma das narrativas que se constroem analisando objetos e seus criadores. O segundo, Mechanization takes Command - de Sigfried Giedion -, publicado em 1948, toma o partido da análise da mecanização e seus efeitos na vida quotidiana.

45 - Veja-se, por exemplo, KUHN, Thomas S. The Structure of Scientific Revolutions. Chicago, University of Chicago Press, 1962.

46 - Como exemplo maior é possível citar os dois volumes de MARGOLIN, Victor. A World History of Design; obra que abrange todo o mundo dos tempos pré-históricos à contemporaneidade. Outras obras são mais específicas. Veja-se FIELL, Charlotte \& Peter. The Story of Design: From the Paleolithic to the Present, 2016.

47 - BUCHANAN, Richard \& Margolin, Victor. Discovering Design: Explorations in Design Studies. Chicago, University of Chicago Press, 1995.

48 - BUCHANAN, Richard. "Rhetoric, Humanism and Design”. in: BUCHANAN, Richard \& Margolin, Victor.

Discovering Design: Explorations in Design Studies. Chicago, University of Chicago Press, 1995, pp. 27 - 28.
}

Cadernos Cajuína, V. 5, N. 2, 2020, p. 96-114. 


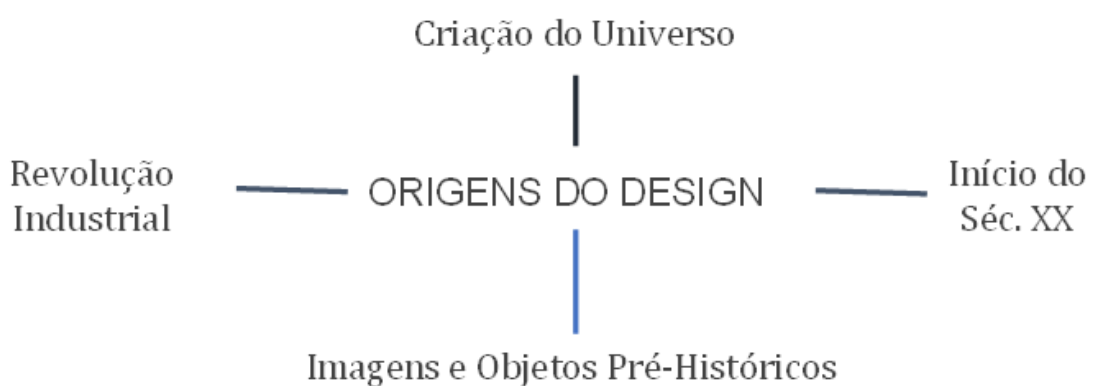

Evidentemente, todos esses "pontos de partida" são, não apenas arbitrários como carecem de - volta-se ao velho problema -, de uma "definição" de design: dependendo do que se acredita ser design constrói-se - pirandellianamente -, a imagem de uma "História": assim é se lhe parece. Ou seja, uma "farsa filosófica". Por que não atribuir a "origem” do design ao Renascimento Italiano? Quando se fala de "design" se quer dizer apenas "design de produto"? O que se pode manter (e o que se deve descartar) na construção de uma perspectiva histórica que busque descrever a natureza do design?

É óbvio que não existe resposta. Ou, pelo menos, não existe uma resposta dentro da perspectiva clássica de um "sujeito" que deseja descrever um "objeto" - neste caso, a "história" -, nos termos de Leopold von Ranke: wie es eigentlich gewesen; ou seja, mostrar o passado como ele realmente foi.

Resulta que, para se poder começar a pensar a História do Design de acordo com uma perspectiva tal como a inaugurada por Heidegger e Gadamer muito ainda tem que ser feito. É necessário que a História se debruce sobre sua própria historicidade. Não basta apenas especular sobre "começos" e "fins"; descrever particularidades estéticas; exaltar funcionalidades ou tecnologias; explorar possibilidades de consumo. Isso tudo. E ainda mais.

Como no conto de Borges, a História é um Livro de Areia - porque nem a areia e nem o livro têm princípio ou nem fim. Termino pois, com a mesma perplexidade com que comecei o texto; invocando - ainda uma vez -, Jorge Luis Borges cujo personagem, ao adquirir um livro, foi desafiado pelo "vendedor" a achar a primeira página:

"Me pidió que buscara la primera boja.

Apoyé la mano izquierda sobre la portada y abrí con el dedo pulgar casi pegado al indice. Todo fue inútil: siempre se interponian varias hojas entre la portada y la mano. Era como si brotaran del libro.

- Abora busque el final.

También fracasé (...." 
Venho buscando uma chave hermenêutica para a leitura da História do Design.

\section{BIBLIOGRAFIA}

BLEICHER, Joseph. (1980): Contemporary Hermeneutics: Hermeneutics as Method, Philosophy and Critique. London, Routledge \& Kegan Paul, 1983.

BORGES, Jorge Luis. Obras completas: (1923-1972). Volume 1, Buenos Aires, Emece, 1974.

BUCHANAN, Richard \& Margolin, Victor. Discovering Design: Explorations in Design Studies. Chicago, University of Chicago Press, 1995.

BUCHANAN, Richard. "Rhetoric, Humanism and Design". in: BUCHANAN, Richard \& Margolin, Victor. Discovering Design: Explorations in Design Studies. Chicago, University of Chicago Press, 1995.

BYARS, Mel. (1994): The Design Encyclopaedia. London/New York, Laurence King / MOMA, 2004.

DENIS, Rafael Cardoso. (1998) "Design, Cultura Material e o Fetichismo dos Objetos". in: Arcos. Volume 1. Número Único.

DILTHEY, Wilhelm. «Origens da Hermenêutica». in: MAGALHÃES, Rui (org.):Textos de Hermenêutica. Tradução de Alberto Reis, Porto, Rés, 1984.

ERLHOFF, Michael \& MARSHALL, Timothy. (Eds.) (2003): Design Dictionary: Perspetives on Design Terminology. Basel, Birkhäuser, 2008.

FALLAN, Kjetil. Design History: Understanding theory and method. Oxford, Berg.

FIELL, Charlotte \& Peter. The Story of Design: From the Paleolithic to the Present, 2016.

GADAMER, Hans-Georg. (1960): Wahrheit und Methode. Tradução de Garrett Barden e John Cumming: Truth and Method. New York, Crossroad, 1985.

GIEDION, Sigfried. Mechanization takes Command: a contribution to anonymous history. New York, Oxford University Press, 1948.

HARTMAN, Charles. "Han Yü”. in: NIENHAUSER Jr., William H. (Ed.) (1986): The Indiana Companion to Traditional Chinese Literature. Indiana University Press.

HEIDEGGER, Martin. (1935): Einführung in die Metaphysik. Tradução de Emmanuel Carneiro Leão: Introdução à Metafísica. 2. ed. Rio de Janeiro, Tempo Brasileiro, 1978.

KUHN, Thomas S. The Structure of Scientific Revolutions. Chicago, University of Chicago Press, 1962. 
MARGOLIN, Victor. "História do Design e Estudos em Design". in: A Política do Artificial. Tradução de Cid Knipel Moreira. Rio de Janeiro, Civilização Brasileira, 2014.

MARGOLIN, Victor. A World History of Design. Volume 1: Prehistoric Times to World War I. London, Bloomsbury, 2017.

MORAlES, Luis Rodríguez. (1989): Para una Teoría del Diseño. Cidade do México, Universidad Autónoma Metropolitana de Azcapotzalco, 2008.

ORTIZ-OSÉS, Andrés. (1983): Antropologia Hermenêutica. Tradução de Laura Ferrereira dos Santos: Antropologia Hermenêutica. Lisboa, Escher, 1989.

OSHO. (1978): The Wisdom of the Sands. Tradução de Swami Anand Nisargan: A Sabedoria das Areias: Discursos sobre o Sufismo. Volume I. São Paulo, Editora Gente, 1999.

OUTHWAITE, William.. «Hans-Georg Gadamen». in: SKINNER, Quentin (ed.) ((1985): The Return of Grand Theory in Social Science. Canto Books. Cambridge, Cambride University Press, 1990.

PALMER, Richard E. (1969): Hermeneutics - Interpretation Theory in Schleiermacher, Dilthey, Heidegger and Gadamer. Tradução de Maria Luísa Ribeiro Ferreira: Hermenêutica. Lisboa, Edições 70, 1986.

PAPANEK, Victor. Design for the Real World: Human Ecology and Social Change. London, Pantheon Books, 1972.

PARSONS, Glenn. The Philosophy of Design. Cambridge, Polity Press, 1990.

PEVSNER, NIKOLAUS. Pioneers of the Modern Movement: From William Morris to Walter Gropius. London, Faber \& Faber, 1936.

REVEL, Jacques. (1999): "História e ciências sociais: Leituras de um debate francês". in: Proposições: Ensaios de História e Historiografia. Rio de Janeiro, EdUERJ, 2009.

VEYNE, Paul. (1971): Comment on écrit l'histoire. Tradução de Alda Baltar e Maria Auxiliadora Kneipp: Como se escreve a história; Foucault Revoluciona a História. Brasília, Editora da Universidade de Brasília, 1982.

VEYNE, Paul. "Introdução". in: História e historicidade. Tradução de Geminiano Cascais Franco, Lisboa, Gradiva, 1988.

VEYNE. Paul. (2008): Foucault, Sa pensée, sa personne. Tradução de Luís Lima: Foucault, O pensamento, a pessoa. Lisboa, Edições Texto e Grafia, 2009. 